\title{
PERANCANGAN ULANG TATA LETAK RUANG UNIT REKAM MEDIS DALAM PENINGKATAN PRODUKTIVITAS KERJA PEREKAM MEDIS DI RUMAH SAKIT PARU SURABAYA
}

\author{
Malia Rikza Dinia*, Bambang Nudji*, \\ *Program Studi D3 RMIK, STIKES Yayasan RS. Dr. Soetomo \\ Email : maliarikza83@gmail.com
}

\begin{abstract}
ABSTRAK
Penyelenggaraan rekam medis yang bermutu dan efektif diperlukan adanya sarana penunjang yang memadai, diantaranya adalah kondisi tata letak unit rekam medis dan ruang penyimpanan berkas rekam medis. Apabila tata letak ruang tidak memenuhi standar tentu akan mengganggu kenyamanan perekam medis. Unit Rekam Medis di Rumah Sakit Paru lantai dua merupakan tempat penyimpanan BRM rawat jalan, rawat inap dan ruang kerja perekam medis urusan pelaporan, filing dan kepala RM. Pengaturan tata letak ruang unit rekam medis belum baik. Penelitian ini bertujuan merancang ulang ruang rekam medis dalam meningkatkan produktivitas kerja perekam medis di Rumah Sakit Paru. Menggunakan metode penelitian deskriptif. Subyek adalah ruang Unit Rekam Medis lantai dua Rumah Sakit Paru. Variabel penelitian adalah Unit rekam medis, urusan filing, urusan pelaporan, urusan kepala rekam medis, perekam medis, tata letak ruang unit rekam medis, tata letak ruang urusan filing, tata letak ruang urusan pelaporan, tata letak ruang urusan kepala rekam medis dan produktivitas kerja. Hasil penelitian adalah letak meja kepala rekam medis rancangan baru ruang unit rekam medis paling belakang dari meja filing, meja scanner dan meja pelaporan. Hasil pernyataan sangat setuju oleh perekam medis terhadap rancangan ulang ruang unit rekam medis dapat meningkatkan produktivitas kerja perekam medis di Rumah Sakit Paru.
\end{abstract}

Kata Kunci : Rancangan Ulang, Tata Letak Ruang, Produktivitas Kerja

\begin{abstract}
Providing a quality and effective medical record is required adequate supporting facilities, among others are medical record space layout condition and medical record file storage space. If space layout doesn't meet the standards will interfere leisure medical recorder. Medical Record unit at the second floor Paru Hospital are storage space of outpatient medical record files, inpatient and medical recorder workspace the reporting section, filing and head of medical record. The setting of the medical record unit layout is not good. This study aims to redesign the layout of the medical records to increase medical recorder work productivity at Paru Hospital. Using descriptive research method. The subject of the study was space of Medical Record unit at the second floor Paru Hospital. The variable in this study is medical record unit, filing section, reporting section, head of medical record, medical recorder, the layout of the medical record unit space, the layout of the filing section, the layout of the reporting section, the layout of the head of medical record and work productivity. The study result is location from head of medical record table at new design of the medical record unit space most back of the filing table, scanner table and reporting table. Result of the statement strongly agree by medical recorder to redesign of the medical record unit space can increase medical recorder work productivity at Paru Hospital.
\end{abstract}

Keyword : Redesign, Space Layout, Work Productivity. 
PENDAHULUAN

Menurut Peraturan Menteri Kesehatan (Permenkes) Republik Indonesia (RI) Nomor : 56 tahun 2014 tentang Klasifikasi dan Perizinan Rumah Sakit menyatakan bahwa, rumah sakit adalah institusi pelayanan kesehatan yang menyelenggarakan pelayanan kesehatan perorangan secara paripurna yang menyediakan pelayanan rawat inap, rawat jalan, dan gawat darurat. Pelayanan kesehatan paripurna adalah pelayanan kesehatan yang meliputi promotif, preventif, kuratif, dan rehabilitatif. Dalam pelaksanaannya sebagai pemberi pelayanan kesehatan, rumah sakit harus menyelenggarakan pengelolaan rekam medis yang baik.

Menurut Gemala Hatta (2010:73) menyatakan bahwa, rekam medis adalah berkas yang berisikan catatan dan dokumen tentang identitas pasien, pemeriksaan, pengobatan, tindakan dan pelayanan lain kepada pasien pada sarana pelayanan kesehatan. Dalam menyelenggarakan rekam medis yang bermutu dan efektif diperlukan adanya sarana penunjang yang memadai, diantaranya adalah kondisi tata letak unit rekam medis dan ruang penyimpanan berkas rekam medis, apabila tata letak ruang tidak memenuhi standar tentu akan mengganggu kenyamanan perekam medis.
Tata letak ruang kerja yang baik dapat meningkatkan produktivitas kerja dan mampu memberikan kenyamanan secara fisik maupun sosial psikologis. Pengoptimalan fasilitas penunjang serta pengaturan tata letak ruang yang nyaman bagi petugas diperlukan agar tercapai keserasian antara manusia dan pekerjaannya dengan tujuan tercapainya produktivitas dan efisiensi yang setinggitingginya (Suma’mur, 1989:1).

Dalam penyelenggaraannya, ruang kerja perekam medis dan ruang penyimpanan berkas rekam medis harus terpisah. Baik terpisah dengan ruang yang berbeda maupun dengan adanya sekat pembatas. Menurut Wursanto (1991 : 221) Ruangan penyimpanan arsip sebaiknya terpisah dari ruangan kantor lain untuk menjaga keamanan arsip-arsip tersebut mengingat bahwa arsip tersebut sifatnya rahasia, mengurangi lalu lintas pegawai lainnya, dan menghindari pegawai lain memasuki ruangan sehingga pencurian arsip dapat dihindari.

Berdasarkan survei awal dan penelitian yang dilakukan di Unit Rekam Medis Rumah Sakit Paru Surabaya di lantai dua yang berukuran 7,85 m x 6,30 m merupakan tempat penyimpanan berkas rekam medis rawat inap, rawat jalan dan sebagai ruang kerja perekam medis urusan pelaporan, perekam medis urusan filing dan urusan kepala rekam medis. Ruang 
penyimpanan berkas rekam medis tersebut berhubungan langsung dengan ruang kerja perekam medis tanpa diberi sekat sebagai pemisah dan hanya ada satu pintu sebagai akses keluar masuk. Pengaturan tata letak yang belum baik membuat perekam medis tidak nyaman saat bekerja.

Berdasarkan latar belakang dari masalah yang ada, peneliti mengambil penelitian tentang Perancangan Ulang Tata Letak Ruang Unit Rekam Medis Dalam Peningkatan Produktivitas Kerja Perekam Medis Di Rumah Sakit Paru Surabaya untuk menghasilkan tata letak ruang unit rekam medis yang mampu menghasilkan tingkat produktivitas kerja perekam medis yang tinggi di Rumah Sakit Paru Surabaya dalam memberikan pelayanan.

\section{METODE}

Jenis penelitian ini bersifat deskriptif yaitu menggambarkan tentang keadaan di Rumah Sakit Paru Surabaya yang sedang dihadapi pada situasi sekarang. Pengumpulan data dilakukan dengan cara melakukan pengukuran ruang yang dicatat dalam lembar observasi dan membagikan kuesioner kepada perekam medis mengenai penilaian rancangan ulang ruang unit rekam medis Rumah Sakit Paru Surabaya.

\section{HASIL DAN PEMBAHASAN}

Berdasarkan hasil penelitian diperoleh gambaran ruang unit rekam medis lantai 2 Rumah Sakit Paru Surabaya sebagai berikut :

Gambar 1 Ruang Unit Rekam Medis Lantai Dua Rumah Sakit Paru Surabaya Tahun 2017

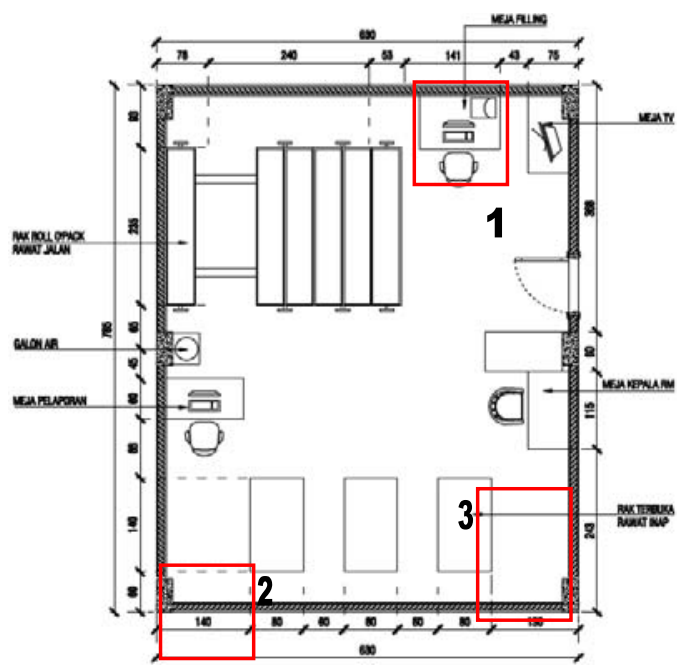

Tata Letak Ruang Unit Rekam Medis Rumah Sakit Paru Surabaya

Berdasarkan Gambar 1 ruang Unit Rekam Medis terdiri dari tempat kerja perekam medis meliputi urusan filing, urusan pelaporan, urusan kepala rekam medis dan ruang penyimpanan berkas rekam medis rawat inap dan berkas rekam medis rawat jalan yang berhubungan langsung tanpa adanya sekat sebagai pemisah. Ruang Unit Rekam Medis Rumah Sakit Paru Surabaya ini berukuran 7,85 m $\mathrm{x} \quad 6,30 \mathrm{~m}$. Terdapat rak penyimpanan berkas rekam medis berjenis rak terbuka sebagai tempat penyimpanan berkas rekam medis rawat inap dan rak 
penyimpanan berkas rekam medis berjenis roll o'pack sebagai tempat penyimpanan berkas rekam medis rawat jalan..

Urusan kepala rekam medis terletak dekat dengan pintu akses keluar masuk dan sejajar dengan urusan pelaporan berjarak 4,07 m yang berada di depan rak berjenis terbuka. Didepan urusan pelaporan adalah rak berjenis roll o'pack, didepan kepala rekam medis merupakan urusan filing.

Menurut Wursanto (1991:221) Ruangan penyimpanan arsip sebaiknya terpisah dari ruangan kantor lain untuk menjaga keamanan arsip-arsip tersebut mengingat bahwa arsip tersebut sifatnya rahasia, mengurangi lalu lintas pegawai lainnya, dan menghindari pegawai lain memasuki ruangan sehingga pencurian arsip dapat dihindari.

Ruang Unit Rekam Medis Rumah Sakit Paru Surabaya memiliki luas ruangan dengan ukuran 7,85 m x 6,30 m sebagai ruang penyimpanan berkas rekam medis dan ruang kerja perekam medis tidak memenuhi standar tata letak ruang yang baik. Ruang penyimpanan berkas rekam medis dan ruang kerja perekam medis tersebut saling berhubungan langsung tanpa adanya sekat sebagai pemisah ruangan dan hanya ada satu pintu sebagai akses keluar masuk.

Melihat ukuran luas Unit Rekam Medis yang ada saat ini tidak memungkinkan untuk diberi sekat-sekat dikarenakan ukuran ruangan yang terlalu sempit, untuk itu peneliti menyarankan agar adanya penambahan ruangan untuk ruang kerja perekam medis di depan Unit Rekam Medis saat ini agar ruang kerja perekam medis dan ruang penyimpanan berkas rekam medis bisa terpisah ruangan. Ruang Unit Rekam Medis saat ini menggunakan seluruh ruang sebagai tempat penyimpanan berkas rekam medis rawat jalan dan perekam medis bekerja di ruang kerja yang baru.

\section{Tata Letak Ruang Urusan Filing}

Berdasarkan Gambar 1 pada keterangan nomor 1 tata letak urusan filing terletak dekat dengan rak berjenis roll o'pack. Urusan filing ini berada didepan urusan kepala rekam medis yang letaknya dekat dengan pintu dengan jarak antara urusan filing dan urusan kepala rekam medis adalah 3,68 m. Meja filing berukuran $120 \mathrm{~cm}$ x $80 \mathrm{~cm}$. Pada meja filing ini terdapat komputer dan scanner.

Berdasarkan tanya jawab dengan petugas filing, bagian filing merupakan tempat dimana berkas rekam medis diletakkan sebelum dilakukan penyimpanan berkas rekam medis di rak penyimpanan.

Menurut Depkes RI (2006:80) tentang persyaratan ruang penyimpanan berkas rekam medis yaitu :

1. Ruangan letaknya harus strategis, sehingga mudah dan cepat dalam 
pengambilan, penyimpanan dan distribusi.

2. Harus ada pemisahan ruangan rekam medis aktif dan in aktif.

3. Hanya petugas penyimpanan yang boleh berada di ruang penyimpanan.

Di ruang Unit Rekam Medis Rumah Sakit Paru Surabaya, urusan filing terletak dekat dengan pintu karena lebih sering keluar masuk ruangan untuk mengambil dan mengantar berkas rekam medis ke poli tujuan pasien berobat.

Meja filing terdapat komputer untuk melakukan pengecekan apabila berkas rekam medis tidak ditemukan di rak penyimpanan berkas rekam medis. Sehingga apabila ada berkas rekam medis yang tidak ditemukan pada rak penyimpanan berkas dapat dengan mudah diketahui letaknya. Di meja tersebut juga terdapat scanner untuk melakukan scan pada berkas tertentu yang seharusnya diletakkan di meja yang berbeda. Agar apabila ada perekam medis yang melakukan scan tidak mengganggu perekam medis urusan filing dalam melakukan pekerjaan.

Rancangan ruang penyimpanan berkas rekam medis sudah memenuhi persyaratan ruang penyimpanan, ada satu meja untuk perekam medis bagian filing dan komputer untuk melakukan pengecekan berkas rekam medis yang tidak ditemukan di rak, meja kerja perekam medis urusan filing berada di ruang kerja perekam medis.

\section{Tata Letak Ruang Urusan Pelaporan}

Pada keterangan nomor 2 di ruang Unit Rekam Medis Rumah Sakit Paru Surabaya, urusan pelaporan terletak sejajar dengan urusan kepala rekam medis. Urusan pelaporan berjarak 4,07 m dengan urusan kepala rekam medis. Urusan pelaporan terletak di depan rak berjenis rak terbuka dan didepan urusan pelaporan terdapat rak berjenis roll o’pack. Meja pelaporan ini berukuran $116 \mathrm{~cm}$ x $60 \mathrm{~cm}$ ada komputer dan printer. Terdapat satu kursi untuk perekam medis dan terdapat galon air didepan meja. Urusan pelaporan terletak lebih jauh dari pintu akses keluar masuk.

Di Ruang Unit Rekam Medis Rumah Sakit Paru Surabaya, urusan pelaporan ini terletak lebih jauh dari pintu sehingga tidak terganggu oleh orang yang keluar masuk ruangan karena pekerjaan pelaporan membutuhkan konsentrasi yang penuh. Letak urusan pelaporan harus dekat dengan kepala rekam medis agar sewaktu-waktu apabila kepala rekam medis membutuhkan data laporan yang dibutuhkan, laporan bisa tersedia dengan cepat. Letak saat ini masih belum bisa dikatakan baik dikarenakan masih satu ruang dengan rak penyimpanan berkas rekam medis.

Rancangan tata letak Unit Rekam Medis yang baru, urusan pelaporan terletak 
diantara meja scanner dan meja kepala rekam medis. Untuk memudahkan perekam medis bagian pelaporan melakukan scan data dan memberikan data yang dibutuhkan oleh kepala rekam medis dengan jarak yang dekat. Urusan pelaporan dekat dengan urusan kepala rekam medis karena lebih sering melakukan interaksi.

\section{Tata Letak Ruang Urusan Kepala Rekam Medis}

Pada keterangan nomor 3 urusan kepala rekam medis terletak di dekat pintu akses keluar masuk dan sejajar dengan urusan pelaporan serta terletak di depan rak berjenis rak terbuka tempat penyimpanan berkas rekam medis rawat inap. Didepan urusan kepala rekam medis merupakan urusan filing. Terdapat satu kursi untuk kepala rekam medis dan satu kursi untuk kursi tamu didepan meja kepala rekam medis.

Menurut Diklat Jarak Jauh Sepala (1994:11) dalam mengatur tata letak tempat duduk dan peralatan dalam ruangan, kantor Pimpinan ditempatkan dibagian belakang para pegawainya.

Di Ruang Unit Rekam Medis Rumah Sakit Paru Surabaya, urusan kepala rekam medis terletak dekat dengan pintu akses keluar masuk sejajar dengan urusan pelaporan dan didepan urusan kepala rekam medis merupakan urusan filing.

Berdasarkan tanya jawab yang dilakukan dengan kepala rekam medis, kepala rekam medis dan perekam medis yang bekerja di ruang Unit Rekam Medis saat ini sudah merasa tidak nyaman dengan ruang kerja saat ini dikarenakan ruang kerja dan tempat penyimpanan berkas rekam medis menjadi satu ruangan dengan rak penyimpanan berkas rekam medis dan pengaturan tata letak ruang yang tidak baik.

Rancangan tata letak unit rekam medis Rumah Sakit Paru Surabaya yang baru ini, meja kerja kepala rekam medis terletak di bagian paling belakang dari meja filing, meja scanner dan meja pelaporan. Letak meja kepala rekam medis pada rancangan yang baru ini terletak lebih jauh dari pintu utama ruang kerja dan dekat meja pelaporan karena kepala rekam medis rumah sakit dan bagian pelaporan lebih sering berinteraksi mengenai data laporan rekam medis. Letak ini lebih privasi dikarenakan kepala rekam medis sering menerima tamu.

\section{Rancangan Ruang Unit Rekam Medis Rumah Sakit Paru Surabaya}

Gambar 2 Rancangan Ruang Unit Rekam Medis Lantai Dua Rumah Sakit Paru Surabaya Tahun 2017

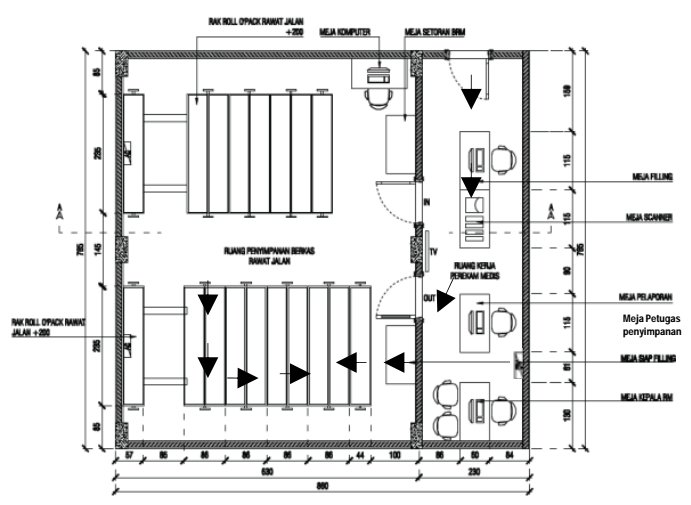


Rancangan unit rekam medis ada penambahan luas ruangan dengan ukuran $2,30 \mathrm{~m}$ x 7,85 m untuk ruang kerja perekam medis. Luas rancangan seluruhnya 8,60 m x 7,85 m. Luas ruangan saat ini seluruhnya digunakan sebagai ruang penyimpanan berkas rekam medis rawat jalan dengan 2 rak roll o'pack, 1 meja komputer untuk pengecekan berkas terletak dekat jendela, 1 meja setoran BRM, 1 meja BRM siap filing dan ruang tambahan digunakan sebagai tempat kerja perekam medis yang diisi meja filing, meja scanner, meja pelaporan dan meja kepala rekam medis. Terdapat 1 pintu masuk utama untuk ruang kerja rekam medis dan 2 pintu akses masuk dan keluar ruang penyimpanan berkas rekam medis.

Berdasarkan Gambar 1 tempat penyimpanan berkas rekam medis dan tempat kerja perekam medis menjadi satu ruangan tanpa diberi sekat sebagai pemisah ruang.

Kekurangan :

a. Rak penyimpanan berkas rekam medis dan ruang kerja perekam medis dalam satu ruangan.

b. Pintu akses keluar masuk hanya satu

c. Jarak antar rak terbuka tidak sama

Kelebihan :

a. Ruangan yang terlihat luas

b. Ruang gerak leluasa

Berdasarkan Gambar 2 Rancangan Ruang Unit Rekam MedisLantai Dua
Rumah Sakit Paru Surabaya Tahun 2017 rancangan ruang Unit Rekam Medis sudah mampu memenuhi standar tata ruang yang baik dengan pemisahan ruangan antara ruang penyimpanan berkas rekam medis dan ruang kerja perekam medis. Rancangan diatas dilakukan penambahan luas ruangan untuk ruang kerja perekam medis.

Kekurangan :

a. Penambahan rak membutuhkan biaya yang mahal

b. Ruang kerja lebih kecil

Kelebihan :

a. Ruang penyimpanan berkas dan ruang kerja terpisah

b. Ruang penyimpanan bisa menampung berkas lebih banyak

c. Ruang kerja lebih nyaman dan privasi

d. Konsentrasi perekam medis tidak terganggu

e. Ada pintu akses masuk dan keluar

Peneliti mengusulkan agar seluruh ruang Unit Rekam Medis saat ini digunakan sebagai tempat penyimpanan berkas rekam medis rawat jalan dan satu meja komputer untuk pengecekan berkas yang diletakkan dekat jendela seperti gambar diatas. Dua pintu sebagai akses keluar dan akses masuk ruang penyimpanan berkas rekam medis. Di ruang kerja perekam medis ada empat meja yaitu meja filing, meja scanner, meja 
pelaporan dan meja kepala rekam medis dengan jarak yang sudah disesuaikan.

Rancangan tata letak ruang Unit Rekam Medis di Rumah Sakit Paru Surabaya sudah memenuhi keempat aspek Tata Ruang Kantor yang terdiri dari :

a. Azaz Jarak Terpendek

Mulai dari kegiatan filing hingga pelaporan sampai kepala rekam medis.

b. Azaz Rangkaian Kerja

Mulai dari perekam medis yang melakukan pekerjaan filing hingga kepala rekam medis sudah ditempatkan sesuai rangkaian urutan kerja dan menempati meja sesuai pekerjaannya.

c. Azaz Penggunaan Segenap Ruang

Ruangan baru ini memanfaatkan seluruh ruang yang ada sehingga tidak ada ruang yang kosong. Adanya penambahan rak roll o’pack untuk ruang penyimpanan berkas rekam medis. Pada ruang kerja perekam medis ada TV. Sehingga seluruh ruang digunakan tidak ada ruang yang sia-sia.

d. Azaz Perubahan Susunan Tempat Kerja

Penempatan susunan meja kerja dan kursi serta peralatan lainnya posisinya dapat diubah atau disusun kembali dengan mudah.
Gambar 3 Potongan Rancangan Ruang Unit Rekam Medis Lantai Dua Rumah Sakit Paru Surabaya Tahun 2017

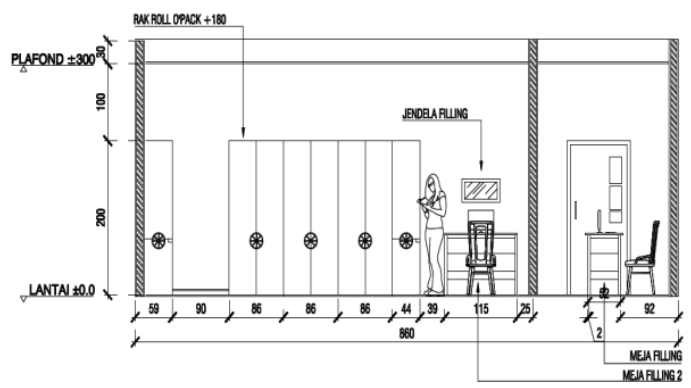

Merupakan tampilan rancangan ruang Unit Rekam Medis lantai dua posisi seorang perekam medis berada di dalam ruang penyimpanan berkas rekam medis dan ruang kerja Unit Rekam Medis Rumah Sakit Paru Surabaya.

Alur rekam medis meliputi alur perekam medis di ruang penyimpanan dan perekam medis di ruang kerja.

a. Alur perekam medis di ruang kerja dimulai dari masuk melalui pintu utama $\rightarrow$ perekam medis duduk di meja urusan masing-masing.

b. Alur di ruang penyimpanan dari perekam medis masuk membawa kartu berobat pasien masuk melalui pintu (in) $\rightarrow$ mengambil berkas rekam medis di rak penyimpanan perekam medis keluar apabila berkas rekam medis ditemukan melalui pintu keluar (out). Apabila berkas rekam medis tidak ditemukan perekam medis dari rak penyimpanan mengecek berkas di komputer keluar melalui pintu keluar (out). 
Alur pengembalian berkas dari perekam medis masuk melalui pintu (in) meletakkan berkas di meja setoran dilakukan pemilahan berkas meletakkan $\rightarrow$ berkas di meja siap filing $\rightarrow$ keluar pintu (out).

Alur di ruang kerja perekam medis sudah disesuaikan dengan pekerjaan masing-masing memudahkan perekam medis dalam melakukan pekerjaannya.

Berdasarkan hasil penelitian dari 3 responden (perekam medis) dengan 8 pernyataan didapatkan total seluruh pernyataan sebesar 84 dengan hasil skor akhir 3,5 dinyatakan sangat setuju, bisa dikatakan hasil rancangan ulang ruang unit rekam medis dapat meningkatkan produktivitas kerja perekam medis Rumah Sakit Paru Surabaya.

\section{SIMPULAN}

Ruang unit rekam medis saat ini seluruhnya digunakan sebagai tempat penyimpanan berkas rekam medis rawat jalan dan perekam medis di ruang kerja baru.

Satu meja perekam medis urusan filing untuk pengecekan berkas rekam medis yang tidak ditemukan di rak penyimpanan, meja kerja perekam medis urusan filing berada di ruang kerja.

Urusan pelaporan terletak diantara meja scanner dan meja kepala rekam medis, urusan pelaporan dekat dengan kepala rekam medis karena lebih sering berinteraksi.

Urusan kepala rekam medis sering menerima tamu terletak lebih privasi dan terletak dekat urusan pelaporan.

Letak meja kepala rekam medis pada rancangan baru ruang unit rekam medis paling belakang dari meja filing, meja scanner dan meja pelaporan.

Alur kerja di ruang kerja dan ruang penyimpanan sesuai dengan pekerjaan perekam medis.

Hasil pernyataan sangat setuju oleh perekam medis terhadap rancangan ulang ruang unit rekam medis dapat meningkatkan produktivitas kerja perekam medis di Rumah Sakit Paru Surabaya.

\section{DAFTAR PUSTAKA}

Antoni, Aris, M. Mun'im Hendrawi, dan Ulfah Sukmasari. 2014. Tinjauan Tata Letak Ruang Guna Kelancaran Proses Pelayanan Rekam Medis di UKRM BLUD RSU Banjarbaru tahun 2014. Jurkessia. Volume 5 (2).

Depkes RI. 1994. Pedoman Pengelolaan Rekam Medis Rumah Sakit di Indonesia. Direktorat Jenderal Bina Pelayanan Medik. Jakarta.

Depkes RI. 2006. Pedoman Penyelenggaraan dan Prosedur Rekam Medis Rumah Sakit di Indonesia. Direktorat Jenderal Bina Pelayanan Medik. Jakarta.

Diklat Jarak Jauh Sepala. 1994. Teknik Menata Ruang Kantor. Jakarta: Lembaga Administrasi Negara Republik Indonesia. 
Hatta, Gemala. 2010. Pedoman Manajemen Informasi Kesehatan di Sarana Pelayanan Kesehatan.Jakarta : Penerbit Universitas Indonesia.

Moekijat. 1996. Tata Laksana Kantor Manajemen Perkantoran. Bandung: Mandar Maju.

Notoatmodjo. 2012. Metodologi Penelitian Kesehatan. Jakarta: PT Renika Cipta. Oktamianiza, dan Sinta Andriani. 2016. Tinjauan Kondisi Fisik Ruangan Terhadap Kinerja Petugas Dalam Pengolahan Rekam Medis di RSUD M. Zein Painan. Jurnal Manajemen Informasi Kesehatan Indonesia. Volume 4 (83).

Peraturan Menteri Kesehatan Republik Indonesia Nomor 269/MENKES/PER/III/2008 tentang Rekam Medis.

Peraturan Menteri Kesehatan. 2014. Peraturan Menteri Kesehatan Republik Indonesia Nomor 56 tahun 2014 tentang Klasifikasi dan Perizinan Rumah Sakit.

Sedarmayanti. 2001. Dasar-dasar Pengetahuan Tentang Manajemen Perkantoran. Bandung: Mandar Maju.

Suma'mur. 1989. Ergonomi Untuk Produktivitas Kerja. Jakarta: CV Haji Masagung.

Gie, The Liang. 1996. Administrasi Perkantoran Modern. Yogyakarta: Liberty.

Undang-Undang Nomor 44 Tahun 2009 pasal 5 tentang Rumah Sakit. Surabaya: Anfaka Perdana.

Wignjosoebroto, S. 2003. Ergonomi Studi Gerak dan Waktu. Surabaya: Penerbit Guna Widya. 